\title{
HYPER-PRODUCTION: A NEW METRIC OF MULTIFUNCTIONALITY
}

\author{
Patrick Brouder ${ }^{1}$, Svante Karlsson², Linda Lundmark ${ }^{3}$
}

Received 22 August 2015; Accepted 25 November 2015

\begin{abstract}
Multifunctionality has emerged as the dominant framework for understanding rural socioeconomic landscapes. The central claim of multifunctionality - that rural regions need to be understood as being made up of more than just traditional uses - has led to the incorporation of new rural activities into regional development plans, e.g., tourism. In some places, such post-productive activity is perceived to be slowly replacing productive uses of the land, e.g., agriculture/forestry. However, there is limited empirical evidence to support such claims. Drawing on previous research and data from the Swedish countryside this paper shows that, even as the number of persons employed within traditional activities decreases, the economic output per areal unit and per labour hour is increasing over time and traditional uses still occupy the majority of rural space. Hyper-production is introduced as a new metric for understanding multifunctional regions going forward. The complementary union of economic mainstays, such as agriculture, and newer activities with more quality-of-life benefits, such as tourism, is highlighted in terms of economic diversification, job creation and local social capital development, while the conflict-prone intersection of these two modes is also acknowledged. Understanding hyper-production as a key metric of multifunctionality is thus argued as integral to planning and developing resilient rural regions now and for the future.
\end{abstract}

Key words: agriculture, forestry, hyper-production, multifunctionality, post-productivism, rural, Sweden.

\section{Introduction}

Multifunctionality has emerged as the dominant framework for understanding the socio-economic make-up of rural landscapes. The concept has been much debated in recent years (McCarthy, 2005; Wilson, 2007). However, much of the discussion lacks clear definition of what exactly constitutes multifunctionality. For example, multifunctionality is often applied at the farm-level (Haaland et al., 2011) but is also conceptualised at the regional level (Woods, 2011). Moreover, little research has focused on whether multifunctionality should be considered as a descriptive state or as an evolving, dynamic, process-led concept. In this paper, we argue that multifunctionality must be closely examined in order to reveal its constituent parts since it can only

\footnotetext{
${ }^{1}$ Patrick Brouder, 1. School of Tourism and Hospitality, University of Johannesburg, South Africa; 2. Department of Tourism Studies and Geography, Mid Sweden University, Sweden; e-mail: pbrouder@brocku.ca.

2 Assoc. Prof. Svante Karlsson, Department of Geography \& Economic History, Umeå University, Samhällsvetarhuset Plan 2 \& 3, 90187 Umeå, Sweden; e-mail: svante.karlsson@umu.se.

3 Assoc. Prof. Linda Lundmark, Department of Geography \& Economic History, Umeå University, Samhällsvetarhuset Plan 2 \& 3, 90187 Umeå, Sweden; e-mail: linda.lundmark@umu.se.
} 
be valid as an epistemological framework if its constituents are assessed through empirical investigation. The ultimate goal, then, is to establish hyper-production as one key metric by which multifunctionality can be measured. Elucidating other possible metrics is beyond the remit of this paper but suffice it to say there is much scope for future research to clarify specific metrics under the multifunctionality umbrella. In this paper the focus is on hyper-production at the regional and national scale and we show how multifunctionality must be seen as a dynamical process evolving over the long-term.

We argue that it is imperative to examine the various elements of multifunctionality and how they relate to the rural landscape. We further argue that hyper-production is present and ongoing in the rural landscape despite the apparent decrease in traditional rural activity. The apparent decrease is due to a long-term trend of decreasing labour in traditional rural industries. However, production output increases in agriculture and forestry cannot be explained away by scale economies only. This paper shows that the Swedish agriculture and forestry industries are not in general decline in rural Sweden and we present a new key metric of multifunctionality, i.e., hyperproduction, which is clearly evident in the Swedish countryside. We argue for multifunctionality as the overarching framework with hyper-production as an important metric of multifunctionality. The evidence points to further conceptualising multifunctionality as a dynamic, long-term process rather than as a snap-shot description of the rural landscape. Following Haaland et alia (2011) we argue that multifunctionality at the landscape level must include both productive and recreational (social) values (Haaland et al., 2011) in order to fully grasp the dynamics of rural socioeconomic change. We call for further studies on the dynamic nature of multifunctionality and further studies on hyper-production in different geographical contexts.

We offer a sympathetic critique of 'multifunctionality'. This concept has become somewhat chaotic and needs to be firmly connected to place (i.e., either farm-level or regional level) in order to be interpreted effectively. The meaning of the concept has also become somewhat obscured (cf. Woods, 2011, p. 81, highlights at least three different inflections of the term). Thus, in the following section, we set out what we believe to be a useful working definition of multifunctionality based on the extant literature and at the regional scale. From this, we assert that multifunctionality as a dynamic process must be reduced to its constituent parts in order to be better understood and compared across regions. Then we present one metric - hyper-production - which we believe is a key element in better understanding multifunctionality. Finally, we link hyper-production to other ongoing processes (some well researched and others less so) and call for further studies on the other latent constituents of multifunctionality. Such studies will both bolster the concept and clarify current ambiguities.

\section{Theoretical background}

Multifunctionality, the idea that rural landscapes typically produce a range of commodity and noncommodity use values simultaneously and that policy ought to recognize and protect that entire range of values, has received substantial attention in the field in recent years... It has also been widely debated in cognate fields, including rural sociology, agricultural economics, and environmental economics (Multifunctionality, McCarthy, 2005, p. 774, Progress in Human Geography).

Multifunctionality has also been conceptualised as a spectrum of decision-making between productivism and non-productivism (Wilson, 2001). The decision-making aspect is important since it highlights that use of the term 'multifunctionality' is a powerful rhetoric device for rural researchers and policy makers. As such it functions as a rural place-maker as well as a framework for understanding the complex countryside of the day in Europe, as elsewhere.

We support McCarthy's claim that multifunctionality is poised to become the best framework to interrogate rural dynamics (McCarthy, 2005). However, in the decade since his seminal paper, multifunctionality has become somewhat obscured as few attempts have been made to pin down its definition and as it has been applied to both the micro (farm) and regional levels. Over time there indeed appears to be a change from a traditional industrial base in natural resource-oriented activities towards a more diversified rural economy but the persistence of productive uses of the rural landscape demands closer examination of the processes of change (Evans et al., 2002; 
Hoggart \& Paniagua, 2001; Walford, 2003; Wilson, 2001). What is required today is an epistemological fortification of multifunctionality which both validates its place as the best framework for understanding rural change yet reduces it to its constituent parts in order to understand the geographical and longitudinal (and sometimes differing) outcomes present in the myriad case studies from, for example, rural sociology to tourism, while also accounting for the inertia of certain traditional uses even in the light of new and emerging uses, e.g., a consolidating but not retreating agricultural sector.

Wilson (2001) argues multifunctionality has global relevance and indeed it is more reflective of pre-modern relationships with the land which included many conditions deemed new in postmodern conceptualisations of rural (read, Western European) landscapes (Wilson \& Rigg, 2003). However, Wilson (2001) sets out multifunctionality as trajectories along which individual farm businesses move, ranging between the productive and the non-productive. We hold that multifunctionality, while having relevance at the individual farm-unit level, has far greater potential at the regional and national levels. The relatively expansive rural landscape of Sweden supports this view. Ednarsson (2006), for example, shows the existence of carnivore tourism in areas where forestry and agriculture still dominate, and other Nordic scholars highlight major tourism development related to second homes, although it is suggested that this is based on the Nordic heritage and therefore should not be seen as a new phenomenon (Müller, 2011; Vepsäläinen \& Pitkänen, 2010). Haaland et alia (2011) discuss multifunctional planning highlighting the importance of including both economic, ecological and social aspects and they conclude that new functions can open up new financial opportunities even though conflicts may also appear. Clearly, this refers to a regional or national view rather than a farm-unit view. McCarthy's (2005) definition remains open to interpretations beyond the farm-unit level and while the micro-level remains important, we focus our attention on multifunctional regions and also examine the national context.

McCarthy's (2005) call for metrics by which to measure multifunctionality needs serious consideration and a clearer understanding of the elements which make up multifunctional regions must be reached. Here, the link between the spaces of flows and the spaces of place (Castells, 2004) helps to conceptualise the common ground between areas of action and areas of affinity it is the intersection of these flows and places where the conflict, complementarity, and confusion over multifunctional uses is to be found. However, conflict between competing land uses is not the dominant situation in rural areas by any measure with landowners open, in principle, to nonproductive or post-productive uses (Church \& Ravenscroft, 2008). Rural researchers are obviously drawn to conflict 'hotspots' and large-scale land use developments also attract the attention of the general public more than the mundane incremental changes, e.g., proposals for new national parks, exploration of new mineral resources, and the opening of new hydroelectric power facilities are always more prone to conflict (Keskitalo \& Lundmark, 2010; Lundmark \& Stjernström, 2009; Sæpórsdóttir, 2012). However, a 'multifunctional inventory' of an entire region or nation would most likely show far more incremental change across the land and relatively few hotspots. Such an inventory requires a number of metrics by which to measure change and we propose one in this paper.

\section{Hyper-production: seeing the forest for the trees}

We define hyper-production, as follows: a key metric of multifunctionality, hyper-production is the manifest phenomenon of the output gains per worker in small and medium holdings over the long-term in the rural economy typically found in the highly-mechanised agriculture and forestry sectors. It differs from 'super-production' in that units do not necessarily need to be largescale but the cumulative output of many medium or small holdings results in larger outputs from fewer workers. A further distinction between super-production and hyper-production is the dominance of small and medium sized holdings which may result in a seemingly monotonous productive landscape at the regional (or national) scale but one that also allows for diverse socioeconomic networks which do not preclude the presence of post-productive activity and may even require it for long-term regional survival. In other words, a hyper-productive agricultural sector actually facilitates a multifunctional rural region, as opposed to a super-productive agricultural sector which would constrain it. This is because the nature of small holdings means 
that there will always be a strong group of locals involved in the productive sectors and these individuals are embedded in personal networks across the multifunctional region from the farm and family level to the village and community level, and beyond.

\section{Research, policy, and indicative data from rural Sweden}

In Sweden, post-productive activities in rural areas do not necessarily preclude fordist organisation of traditional economic activities (Almstedt et al., 2014), nor do they necessarily displace them over time, as the term 'post-productive transition' implies (cf. Mather et al., 2006). The previous example of hunting tourism co-existing with agricultural uses (Ednarsson, 2006) shows a clear multifunctional disposition and the lack of long-term growth in tourism employment in the far north shows that any such 'transition' is overstated for most parts of the rural Swedish landscape (cf. Müller \& Brouder, 2014). Related to this, Müller and Ulrich's (2007) paper is a clear example pointing out a remarkable growth in tourism labour in rural areas during recent decades. Implying that it reflects a decline in traditional industrial production and land use, however, is premature. It is, in fact, a reflection of the relative importance of tourism when other sectors are decreasing in employment (Antonson \& Jansson, 2011; Lundmark, 2005; Müller \& Brouder, 2014) compounded by the decline in the number of rural residents from the 1960 s onwards. This stark decline was somewhat tempered by localised reflux through counter-urbanisation in the 1990s but the long-term vector remains consistent (Borgegård et al., 1995; Westlund, 2002).

Although Sweden is one of the largest countries in the EU, less than $10 \%$ of land is under cultivation, due to large tracts of agricultural production impediment such as mountains, lakes, and marshland. Within forestry, industrialised forestry dominates production and land use outside the mountain regions (SNA, 2011). In Sweden, as in most EU countries, the number of small farms has declined in recent decades, with average farm sizes increasing somewhat. While this has helped to improve efficiency and maintain yields, it has also been accompanied by a decline in the working population engaged in agriculture and forestry. However, the majority of farms and forest properties are still family-owned and run, even if some owners live in urban areas some distance from their property. Moreover, many farmers have invested large sums in new machinery, equipment, and buildings. Accelerating the shift towards larger and fewer farms, and even fewer employees, is the fact that the total revenue of the Swedish agricultural sector has remained at essentially the same level in monetary terms over the past ten years so that productivity gains are most parsimoniously achieved through farm-level economies of scale. However, the size of farm units in Sweden is still not anywhere near the level of, for example, North American super-productive units.

Most Swedish rural areas have been experiencing a gradual depopulation. In many respects this depopulation is related to the remarkable industrial innovation of agriculture and rural industry in Sweden in the post-war era (Flygare \& Isacson, 2003). Innovations in production have led to structural changes that have resulted in more specialised firms (Saeter, 2010). The development in Sweden is similar to most Western countries (Trauger, 2008). Production within each industry or farm has grown without giving rise to new jobs. The driving force behind this development is to be found in the interplay between technological and organisational innovations and policy decisions (Flygare \& Isacson, 2003; Saeter, 2010). In 1991 the Swedish parliament passed a reform plan eliminating domestic price regulation and subsidies that was more radical than the reform of the EU's Common Agricultural Policy (CAP) of the day. The changes to the agricultural sector meant that the Swedish accession to the EU (in 1995) was more complicated as much regulation had to be reintroduced into the agricultural sector and, for the first time, the EU was faced with a country where the agricultural sector as a whole did not see any benefits arising from participation in the CAP. Greater emphasis has since been given to general rural development, and some progress has been made on the reduction of current production levels, the containment of future expenditure growth and preparation for the eastward enlargement of the EU. Sweden is now working to promote the (re-)deregulation of the agricultural sector within Europe. Within forestry there is a certain displacement of owners away from the location of their forest holdings which may have implications for how the resource is exploited in the long-term. 
The demographic and socioeconomic changes which have driven strong rural policy in the EU thus address many of the issues raised regarding modern large-scale farming and environmental impacts of forestry, as well as the emergence of the 'new economy' in rural areas. What is needed to counter-balance this 'post-productive turn' is a more detailed appraisal of conditions on the ground and so the rationale for metrics by which to measure multifunctionality is strong. Hyper-production is one metric to be included in the analysis. While there is good reason to point out that a rural, service-oriented resource-use exists to some extent, it must also be emphasised that such a development has occurred alongside, and in relation to, for example, hyper-production (as well as other elements of multifunctionality).

Traditional natural resource uses still dominate in terms of economic output, but this dominance does not necessarily appear in employment statistics, and thus neither in demographic figures. This is simply due to the output gains of hyper-production through innovations in production techniques resulting in substantial output growth without increasing the number of employees. Hyper-production thus appears when shifting the focus away from employment and population trends in favour of studies of land-use and production volumes but retains a focus on the continuingly peopled landscape geography of rural areas.

The visible presence of many clear-cut areas within the forest landscape, several production plants in pulp and paper, world leading forest machine providers operating on regional and national markets and saw mills in traditional rural locations are testament to the continuing productive use of the Swedish landscape (SNA, 2011). Instead the evidence from the landscape presents a story of persistent hyper-productive spaces alongside a growth in a few localised postproductive places, for example, winter sport resorts in the Scandinavian Range mountains (cf. Lundmark, 2005). Hyper-production should also be seen as a positive counter to superproductivism (cf. Woods, 2011) since hyper-productive agriculture and forestry is often smallscale and tied to local ownership and is thus embedded in rural resilience ideals.

This conceptual paper includes some basic longitudinal official data from the Swedish Board of Agriculture (2011) and also data from the Swedish Forest Agency (2010) to augment the research and policy above. A selection of these data has been used to identify production relations beyond employment numbers and the implied population effects. The focus is on production in agriculture and forestry business with one figure presenting a monetary, and the other a volume, perspective. The data presented are basic but are also highly intuitive and, when considered alongside the small-scale family-owned holdings which still dominate Swedish agriculture and forestry, are indicative of a hyper-productive element in rural Sweden. It behoves us all to examine the basic evidence as well as the discourses present. The limited data presented here open the door to both greater reflection in the discourse and deeper quantitative analysis of the metric of hyperproduction in multifunctional landscapes.

Figure 1 shows there has been a remarkable growth in agricultural production value from a longterm perspective. There has been a concomitant decrease in the numbers employed in the agricultural sector. The pattern in the figure implies a state of hyper-production in Swedish agriculture. It clearly shows there is no retreat of agriculture in the Swedish countryside if one is willing to look beyond only labour market numbers. Of course, as Flygare and Isaksen (2003) argue, there is a structural rationalisation with many smaller farms in peripheral areas having shut down and some increase in farm size and related infrastructure. If we consider forestry, the situation is quite similar. The output per hour worked shows remarkable growth. The pattern in both figures reflects innovations in agriculture and forestry technology. The figures clearly show that there are economic dynamics in the Swedish countryside which are incongruent with the concept of a post-productive transition and these dynamics require further study. 


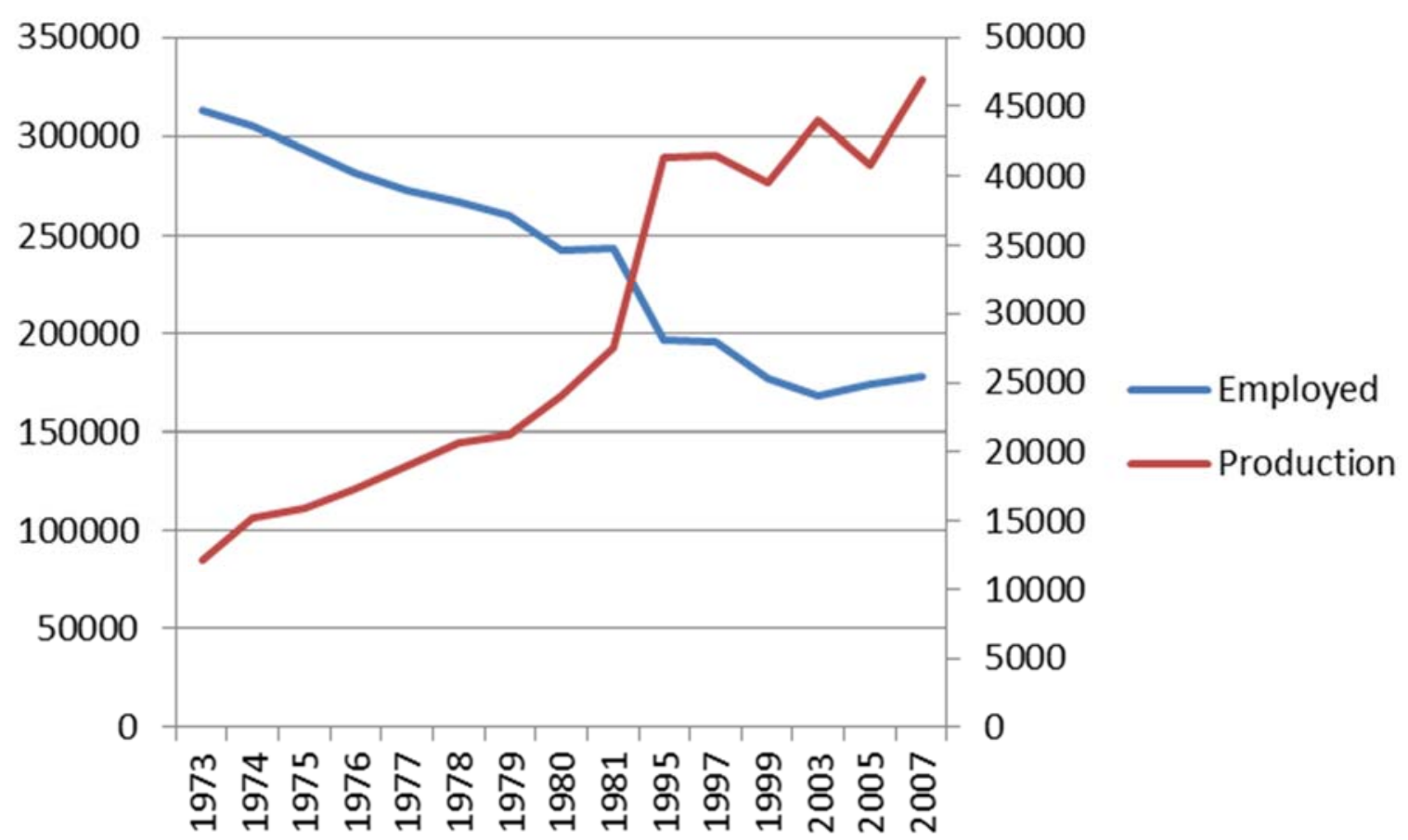

Fig 1. Total employment decrease (from $>300,000$ to $<200,000$ ) for Swedish agri-workers and increasing value of agri-production incl. subsidies (mSEK, unadjusted).

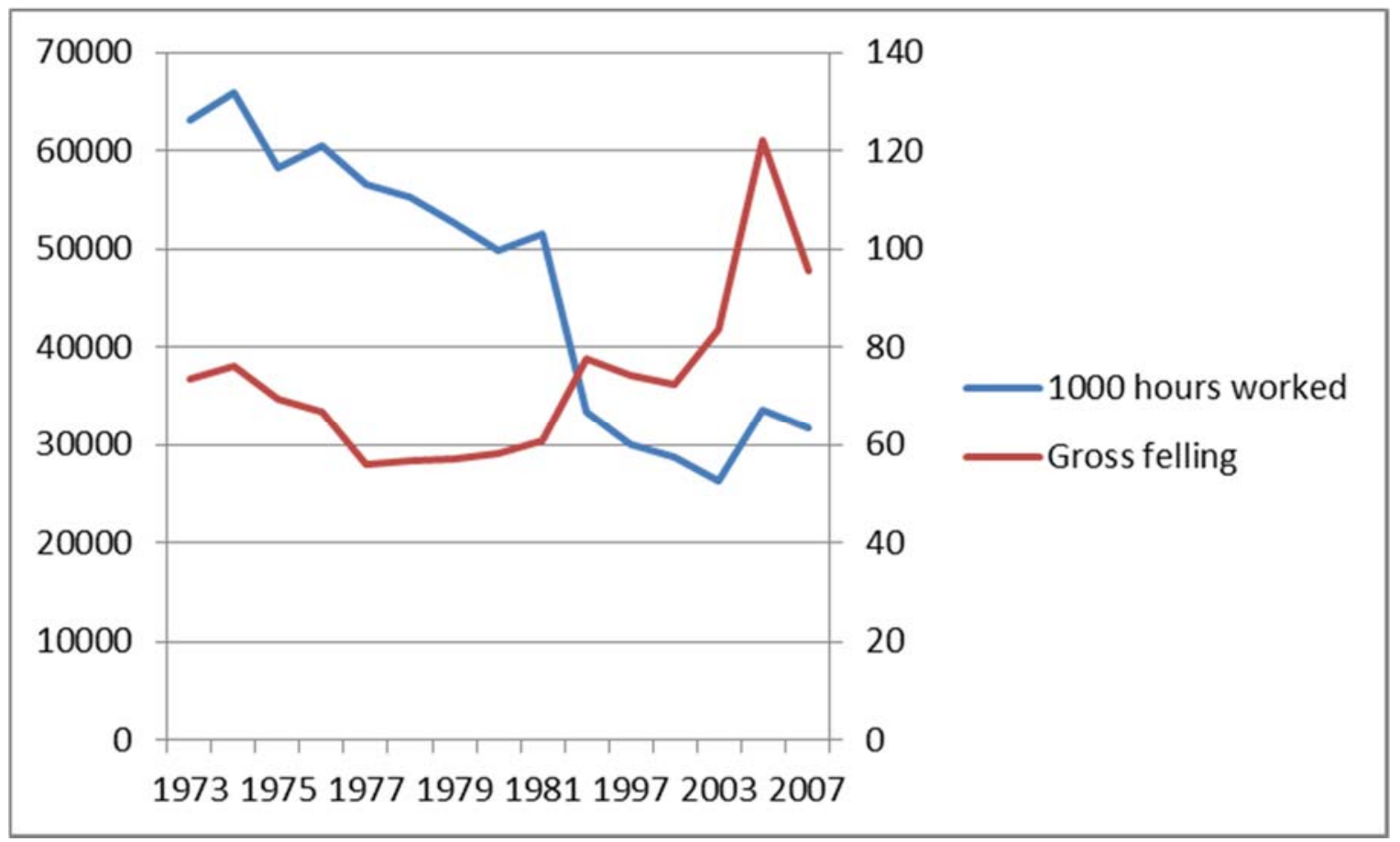

Fig 2. Total employment decrease (in hours worked, from $>60$ million to <35 million) for the Swedish forestry sector and increasing felling of trees (in millions of $\mathrm{m}^{3}$ of forest).

\section{Conclusion and future research}

In this paper we clearly support multifunctionality as the best way to conceptualise the mix of activities within individual agricultural units and across entire regions or nations. McCarthy's (2005) call for multifunctionality as the most fruitful framework under which to study rural areas is supported by the present case of the Swedish agriculture and forestry sectors. However, this applies to the economic activities that are actually performed and not to the regimes that regulate the economic activity such as institutions, political agendas and regional development 
programmes. Of course, geographical variations occur whereby some areas are changing palpably in the direction of post-production while others are still clearly organised along fordist lines. Yet there are few areas in Sweden where agriculture and forestry have withdrawn in favour of nature reserve development or other new uses such as tourism.

Firstly, at the individual level, actors are engaging in both productive and post-productive uses of the land in order to gain revenue - this is regardless of their background although it varies considerably across the groups, i.e., farm tourism is seen as a complement to the productive use of the farm which remains the main source of income (Elands \& Praestholm, 2008). In some cases the growth of farm tourism has led to it becoming the economic mainstay of the family (Brandth \& Haugen, 2011; Busby \& Rendle, 2000) and we call for a closer interrogation of where, how and why this is the case across the geographical spectrum.

Secondly, there is complementarity between productive and post-productive uses in labour. Since the gains in traditional industry productivity have come partly at the expense of labour, rural futures based only on traditional industry employment remain bleak in many areas. Here, postproductive places create room for new employment opportunities and thus migration possibilities (Lundmark, 2005; Lundmark, Ednarsson, \& Karlsson, 2014; Möller, 2012). There is also a gender dimension built in to the labour market dynamics: in the traditional rural economy (the last 60 years or so) most labour was performed by men. With the addition of the post-productive labour market new patterns of gender relations might give certain places a better chance of restructuring and prosperity with more balanced age and gender compositions. We hold that the multifunctional community may be the most resilient (Brouwer \& van der Heide, 2009) in the future as it continues to fill the market town role for traditional rural activities while embracing post-productive use with all of the employment and positive social externalities which that entails (Almstedt et al., 2014; Brouder, 2012a, 2012b; Brouder, 2013; Conway \& Cawley, 2012, Möller, 2012).

Thirdly, we have introduced a new metric of multifunctionality: hyper-production. Hyperproduction is measurable and should be included in future quantitative analyses of rural regions and nations. With multi-functionality as the over-arching framework, hyper-production at the regional level would be measured, as follows: output per worker (over time) in proportion to the number of holdings (with respect to the total area of the region) and linked to the number of owners (of holdings) and workers (in relevant sectors) resident in the region. It is thus quantifiable using regional and national statistical data and easily included in statistical models. It could then be analysed alongside other metrics of multifunctionality.

What other possible metrics of multifunctionality could be tested in future research? Certainly a high level of super-production would be contra-indicative of a multifunctional region but could be included in national analyses of large countries, in particular. We could also posit a metric of hypo-production (where land is used for seemingly traditional rural purposes but where it is producing well below its capacity), e.g., hobby farms in rural areas. Of course, measures of postproductive activity would be vital for understanding the relations between productive and postproductive uses going forward. Finally, basic measures of non-productive land (e.g., nature reserves and national parks) would complete the rural picture. As stated previously, the operationalistion of hyper-production and the other possible metrics of multifunctionality listed above is beyond the remit of this paper but we hold that quantitative analyses incorporating them will enrich our understanding of rural change.

In conclusion, the territorial approach of the OECD's (2006) New Rural Paradigm is a step in the right direction and its local focus and bottom-up approach will most likely lead to further divergence in the socio-economic make-up of rural Europe going forward, i.e., certain postproductive islands will grow while a manufacturing or extractive focus will remain elsewhere. In some areas regional development funds may be better spent on supporting existing industries and thus redressing the legacy of 'spatial-blindness' of top-down policies (Rodriguez-Pose, 2010). This is why metrics such as hyper-production must be incorporated into studies of multifunctionality. The time has come to precise the relationship between traditional industries and the new economic uses of the rural landscape since an increasingly urban population is 
distant from the agriculture and forestry sectors and so may not be in a position to readily see the proverbial forest for the trees.

\section{References}

[1] Almstedt, Å., Brouder, P., Karlsson, S., \& Lundmark, L. (2014). Beyond post-productivism: From rural policy discourse to rural diversity. European Countryside, 6(4), 297-306. DOI: 10.2478/euco-2014-0016.

[2] Antonson, H. \& Jansson, U. (eds.) (2011). Agriculture and forestry in Sweden since 1900. Stockholm, Sweden: Royal Swedish Academy of Agriculture and Forestry.

[3] Borgegård. L, Håkansson, J., \& Malmberg, G. (1995). Population redistribution in Sweden: Long term trends and contemporary tendencies, Geografiska Annaler B, 77(1), 31-45.

[4] Brandth, B. \& Haugen, M. S. (2011). Farm diversification into tourism: Implications for social identity? Journal of Rural Studies, 27(1), 35-44. DOI: 10.1016/j.jrurstud.2010.09.002.

[5] Brouder, P. (2012a). Creative outposts: Tourism's place in rural innovation. Tourism Planning and Development, 9(4), 383-396. DOI: 10.1080/21568316.2012.726254.

[6] Brouder, P. (2012b). Tourism development against the odds: The tenacity of tourism in rural

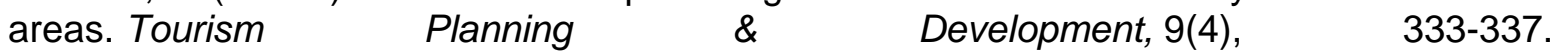
DOI: $10.1080 / 21568316.2012 .726259$.

[7] Brouder, P. (2013). Tourism development in peripheral areas: Processes of local innovation and change in northern Sweden. Östersund: Mid Sweden University.

[8] Brouwer, F. \& van der Heide, C. M. (2009). Multifunctional rural land management: Economics and policies. London: Earthscan.

[9] Busby, G. \& Rendle, S. (2000). The transition from tourism on farms to farm tourism. Tourism Management, 21(6), 635-642. DOI: 10.1016/S0261-5177(00)00011-X.

[10] Castells, M. (2004). The network society. Cheltenham: Edward Elgar.

[11] Church, A. \& Ravenscroft, N. (2008). Landowner responses to financial incentive schemes for recreational access to woodlands in South East England. Land Use Policy, 25(1), 1-16. DOI: 10.1016/j.landusepol.2007.02.003.

[12] Conway, T. \& Cawley, M. (2012). Organizational networking in an emerging ecotourism destination. Tourism Planning and Development, 9(4), 397-409. DOI: 10.1080/21568316.2012.726256.

[13] Ednarsson, M. (2006). Attitudes towards large carnivores and carnivore tourism among tourism entrepreneurs in Sweden. Journal of Alpine Research, 94(4), 58-67.

[14] Elands, B. H. M. \& Praestholm, S. (2008). Landowners' perspectives on the rural future and the role of forests across Europe. Journal of Rural Studies, 24(1), 72-85. DOI: 10.1016/j.jrurstud.2007.02.002.

[15] Evans, N., Morris, C., \& Winter, M. (2002). Conceptualizing agriculture: A critique of postproductivism as the new orthodoxy. Progress in Human Geography, 26(3), 313-332. DOI: 10.1191/0309132502ph372ra.

[16] Flygare, I. A. \& Isacson, M. (2003). Jordbruket i välfärdssamhället 1945-2000 [Agriculture in the Welfare State 1945-2000]. Stockholm: Natur och Kultur/LTs Förlag.

[17] Haaland, C., Fry, G., \& Peterson, A. (2011). Designing farmland for multifunctionality. Landscape Research, 36(1), 41-62. DOI: 10.1080/01426397.2010.536202.

[18] Hoggart, K. \& Paniagua, A. (2001). What rural restructuring? Journal of Rural Studies, 17(1), 41-62. DOI: 10.1016/S0743-0167(00)00036-X. 
[19] Keskitalo, C. E. \& Lundmark, L. (2010). The controversy over protected areas and forestsector employment in Norrbotten, Sweden: Forest stakeholder perceptions and statistics. Society \& Natural Resources, 23(2), 146-164. DOI: 10.1080/08941920802688543.

[20] Lundmark, L. (2005). Economic restructuring into tourism in the Swedish mountain range. Scandinavian Journal of Hospitality and Tourism, 5(1), 23-45. DOI: $10.1080 / 15022250510014273$.

[21] Lundmark, L., Ednarsson, M., \& Karlsson, S. (2014). International migration, selfemployment and restructuring through tourism in sparsely-populated areas. Scandinavian Journal of Hospitality and Tourism, 14(4), 422-440. DOI: 10.1080/15022250.2014.967995.

[22] Lundmark, L. \& Stjernström, O. (2009). Environmental protection: An instrument for regional development? National ambitions versus local realities in the case of tourism. Scandinavian Journal of Hospitality and Tourism, 9(4), 387-405. DOI: 10.1080/15022250903273780.

[23] Mather, A. S., Hill, G., \& Nijnik, M. (2006). Post-productivism and rural land use: Cul de sac or challenge for theorization? Journal of Rural Studies, 22, 441-455. DOI: 10.1016/j.jrurstud.2006.01.004.

[24] McCarthy, J. (2005). Rural geography: Multifunctional rural geographies - reactionary or radical? Progress in Human Geography 29(6), 773-782. DOI: 10.1191/0309132505ph584pr.

[25] Möller, P. (2012). The young adult transition in a tourism dominated rural area. Tourism Planning and Development, 9(4), 429-440. DOI: 10.1080/21568316.2012.726260.

[26] Müller, D. K. (2011). Second homes in Sweden: Between common heritage and exclusive commodity. In B. Hermelin \& U. Jansson (eds.) Placing human geography in Sweden through time and space (pp. 185-207). Stockholm: Svenska Sällskapet för Antropologi och Geografi.

[27] Müller, D. K. \& Brouder, P. (2014). Dynamic development or destined to decline? The case of Arctic tourism businesses and local labour markets in Jokkmokk, Sweden. In A. Viken \& B. Granås (eds.) Tourism destination development: Turns and tactics (pp. 227-244). Farnham: Ashgate.

[28] Müller, D. K. \& Ulrich, P. (2007). Tourism development and the rural labour market in Sweden, 1960-1999. In D. K. Müller \& B. Jansson (eds.) Tourism in peripheries: Perspectives from the far north and south (pp. 85-105). Wallingford: CABI.

[29] OECD (2006). The new rural paradigm: Policies and governance organisation for economic co-operation and development. Paris: OECD.

[30] Rodriguez-Pose, A. (2010). Economic geographers and the limelight: The reaction to the world development report 2009. Economic Geography, 86(4), 361-370. DOI: 10.1111/j.1944-8287.2010.01094.x.

[31] Sæpórsdóttir, A. D. (2012). Tourism and power plant development: An attempt to solve land use conflicts. Tourism Planning and Development, 9(4), 339-353. DOI: $10.1080 / 21568316.2012 .726255$.

[32] Sæter, B. (2010). Agricultural extension services and rural innovation in inner Scandinavia. Norwegian Journal of Geography, 64(1), 1-8. DOI: 10.1080/00291950903557647.

[33] SNA (2011). National atlas of Sweden 15: Manufacturing and services. Stockholm: Norstedts.

[34] Swedish Board of Agriculture (2011). Agriculture in figures: 1866-2007. Stockholm: Swedish Board of Agriculture.

[35] Swedish Forest Agency (2010). Swedish statistical yearbooks of forestry. Jönköping: Swedish Forest Agency.

[36] Trauger, A. (2009). Social agency and networked spatial relations in sustainable agriculture. Area, 41(2), 117-128. DOI: 10.1111/j.1475-4762.2008.00866.x. 
[37] Vepsäläinen, M. \& Pitkänen, K. (2010). Second home countryside: Representations of the rural in Finnish popular discourses. Journal of Rural Studies, 26(2), 194-204. DOI: 10.1016/j.jrurstud.2009.07.002.

[38] Walford, N. (2003). Productivism is allegedly dead, long live productivism: Evidence of continued productivist attitudes and decision-making in South-East England. Journal of Rural Studies, 19(4), 491-502. DOI: 10.1016/S0743-0167(03)00030-5.

[39] Westlund, H. (2002). An unplanned green wave: Settlement patterns in Sweden during the 1990s. Environment and Planning A, 34, 1395-1410. DOI: 10.1068/a3358.

[40] Wilson, G. A. (2007). Multifunctional agriculture: A transition theory perspective. Wallingford: CABI.

[41] Wilson, G. A. (2001). From productivism to post-productivism... and back again? Exploring the (un)changed natural and mental landscapes of European agriculture. Transactions of the Institute of British Geographers, 26(1), 77-102. DOI: 10.1111/1475-5661.00007.

[42] Wilson, G. A. \& Rigg, J. (2003). 'Post-productivist' agricultural regimes and the south: Discordant concepts? Progress in Human Geography, 27(6), 681-707. DOI: 10.1191/0309132503ph450oa.

[43] Woods, M. (2011). Rural. London: Routledge. 